\title{
Allocating active power loss with network reconfiguration in electrical power distribution systems
}

\author{
Ambika Prasad Hota ${ }^{1}$, Sivkumar Mishra ${ }^{2}$, Debani Prasad Mishra ${ }^{3}$, Surender Reddy Salkuti ${ }^{4}$ \\ ${ }^{1,3}$ Department of Electrical Engineering, International Institute of Information Technology Bhubaneswar, Odisha, India \\ ${ }^{2}$ Department of Electrical Engineering, CAPGS, BPUT, Odisha, India \\ ${ }^{4}$ Department of Railroad and Electrical Engineering, Woosong University, Daejeon, Republic of Korea
}

\begin{tabular}{l} 
Article Info \\
\hline Article history: \\
Received Aug 27, 2020 \\
Revised Jan 4, 2021 \\
Accepted Feb 1, 2021 \\
\hline
\end{tabular}

Keywords:

Active power

Distribution network

Load flow

Loss allocation

Network reconfiguration

\begin{abstract}
This paper presents a branch exchange (BE) based heuristic network reconfiguration technique where, the proposed bus classification strategy remodels dynamically as per the modified topology in order to provide a reconfigured network with minimum loss. Further, for fair allocation of the active power losses, it develops a new active power loss allocation (APLA) technique which eradicates the influence of cross-term analytically from loss formulation without any assumptions and approximations. The effectiveness of the proposed procedure has been investigated against other established methods using a 69-bus radial distribution network (RDN). The results of APLA achieved for original and reconfigured 69-bus RDN are found to be promising and judicious as regard to their load demands and geographical locations. The implementation of present reconfiguration procedure provides a total loss reduction benefit of $55.73 \%$ to the utility which highlights the significance of the developed procedure against other established techniques.
\end{abstract}

This is an open access article under the CC BY-SA license.

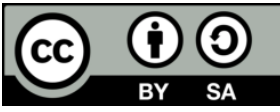

\section{Corresponding Author:}

Surender Reddy Salkuti

Department of Railroad and Electrical Engineering

Woosong University

17-2, Jayang-Dong, Dong-Gu, Daejeon - 34606, Republic of Korea

Email: surender@wsu.ac.kr

\section{INTRODUCTION}

Electrical power distribution system (EPDS) is currently facing numerous challenges due to penetration of distributed energy resources (DERs) such as: energy storing devices, distributed generators (DGs) and power factor correction equipments at the consumer premises [1]-[3]. The penetration of DERs mainly causes reverse current in the network and thus, affects power loss of the EPDS. If power loss of a system increases, its efficiency decreases. One of the solutions to get rid out of this difficulty is to change the network topology i.e., implementation of proper network reconfiguration (NR) technique to achieve an optimal loss providing network. But, execution of NR alters the entire structure of the EPDS from the electrical point of view and simultaneously, brings another possibility to investigate the influence of NR on loss allocations (LAs) of network participants in this modern scenario of power distribution network.

Keeping this in view, a through literature review has been carried out on the established techniques relating to network reconfiguration and power loss allocation. It is verified, in most of the literature, NR [4][6] and LA [7] are considered broadly as two independent area of research still; very few works are identified where both of these have taken together. Oliveira et al. [8] were the first to execute reconfiguration and APLA together for EPDSs with distributed generators, where reconfiguration is carried out through a heuristic principle and power loss allocations with the implementation of a Z-bus technique. However, this 
technique can not be suggested for practical implementation as it suffers from the demerits of the Z-bus scheme of allocation. This drawback is not found in [9], [10] where a BE based NR technique with quadratic LA method $\backslash$ is utilised to award losses to the radial distribution network participants at both scenarios of the RDN (i.e., before and after NR). In [11], a branch current decomposition method as discussed in [12] is employed for allocation of power losses where a group search optimization technique is utilised to achieve the optimum solutions. Similarly, a minimum branch current based circular-updating mechanism is used for obtaining a reconfigured RDN in the proposed method [13]. To allocate losses judiciously among the consumers of the RDN, a current summation approach of LA has been discussed in [14] where the mutual terms of power loss equation are distributed among the consumers and DG owners using a logarithmic scheme of LA. However, this technique is only applicable when participation factors lie within $\{0-2\}$. The authors of [15]-[19] have recommended game theory-based procedures for APLA of EPDSs by utilizing the concept of Shapley value for sharing losses among the network users. But LA procedure generally solved by Shapley value technique faces difficulties of memory burden and time complexcity when applied to larger RDNs. This drawback is not found in the discussed in [20] and [21] as they assign losses according to proportional sharing and power summation principles, respectively. Still, these methods are not awarding exact allocations as they are developed with certain assumptions. To overwhelm this problem the authors of [22] have introduced an exact scheme of LA by analyzing the interrelationship preent between branch currents and their subsequent node voltages. The cross-term decomposition method (CTDM) developed in [23] distributes the mutual powers using loss allocation factors with a minimum error of $4 \%$ between the calculated and true value of DG remuneration. The node voltage-based algorithm developed in [24] provides exact allocations to the RDNs with/without DGs but, it says nothing about DG remuneration. This issue is solved by implementation of a participation-based DG remuneration scheme in [25] where the entire benefits of RDN loss reduction due to distributed generation units are provided to the DG owners.

Keeping above discussed points in view, this paper introduces a node voltage based APLA method। in Section 2 where the impact of cross-term has been wiped out empirically from the power loss equation with proper mathematical formulation. The results of APLA are found to be proper as per load demands and physical locations of the end-users. The detail discussion on the algorithm of BE based NR technique is performed in Section 3. In Section 4, the loss allocation results as obtained for both base and reconfigured 69-bus RDN are compared with that of the other other existing methods to show superiority of the present procedure in contrast to discussed established methods. Finally, the conclusive remarks are provided in Section 5 .

\section{LOSS ALLOCATION METHOD}

This section contains two subsections. First part introduces the bus identification technique used in the entire formulation procedure while the second part discusses regarding the derivation of the developed loss allocation procedure. The entire formulation is carried out by utilizing optimal voltages as obtained through a forward-backward sweep (FBS) based power flow approach [26]. In irder to incorporate DGs into the evaluation procedure, the negative load modelling of generators as discussed in [27], [28] can be implemented to get the net power injections, and with these values the load flow can be carried out further to get desired solutions.

\subsection{Proposed bus identification scheme}

In present strategy, the root node is indexed as ' 1 ' and the successive buses along the main and lateral feeders are numbered in the increasing order as shown in Figure 1. Here, three arrays $(s b[], m f s[]$ and $m t s[]$ ) are proposed for keeping the entire information relating to subsequent buses of the RDN as discussed in [29]. The array $s b[]$ is used for keeping the subsequent nodes of all the branches of the radial distribution network.

Two pointer arrays $m f s[]$ and $m t s[]$ are utilised to store the initial and final memory positions of the successive nodes relevant to each branch of the RDN, respectively. The formations of these arrays are done by utilising input data of the RDN in MATLAB-R2018b environment. 


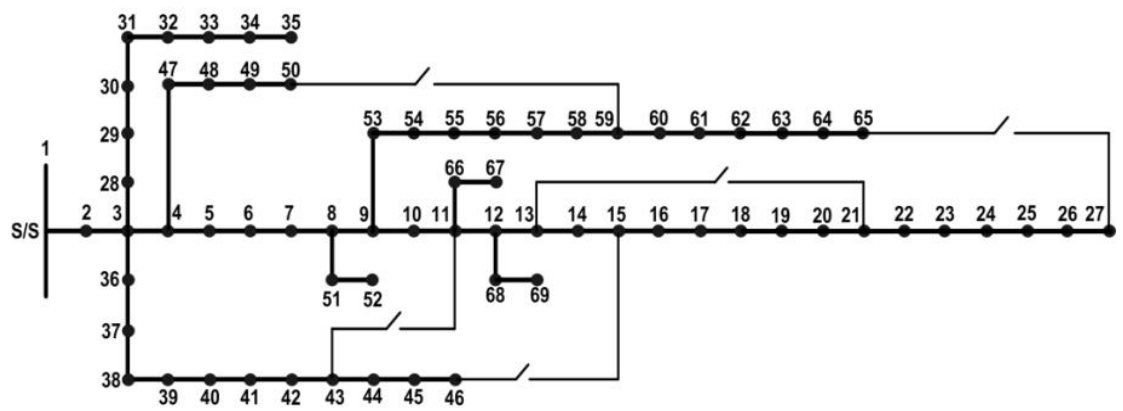

Figure 1. A sample 69-node test distribution system before NR

\subsection{Formulation of the proposed APLA Method}

The load current (LC) at any node- $i$ with net complex power injection $S_{L i}=P_{L i}+j Q_{L i}$ and node voltage $V_{i}$ can be evaluated as (1):

$$
I_{L i}=\left[\frac{P_{L i}+j Q_{L i}}{V_{i}}\right]^{*}=\frac{P_{L i}-j Q_{L i}}{\left(V_{i}\right)^{*}}, \text { for } i=2,3, \ldots \ldots n b
$$

The current of any branch-jj can be estimated by addition of the LCs of the successive consumers (2)

$$
I(j j)=\left[\sum_{i=s b(m f s(j j))}^{s b(m t s(j j))} I_{L i}\right]
$$

The current in a branch-jj can be further explained using equations (1) and (2) as (3),

$$
I(j j)=\sum_{i=s b(m f s(j j))}^{s b(m t s(j j))} \frac{P_{L i}-j Q_{L i}}{\left(V_{i}\right)^{*}}
$$

Active power loss (APL) of any branch-jj can be estimated with branch impedance $Z(j j)$ and branch current $I(j j)$ as (4):

$$
P \operatorname{Loss}(j j)=\operatorname{Real}\left[\left\{|I(j j)|^{2}\right\}\{Z(j j)\}\right]=\operatorname{Real}\left[\left[\{I(j j)\}\{I(j j)\}^{*}\right]\{Z(j j)\}\right]
$$

The APL of the branch-jj can be presented in terms of sending end voltage $(V s)$, receiving end voltage $(V r)$ and the branch current $I(j j)$ as:

$$
\begin{aligned}
& \operatorname{PLoss}(j j)=\operatorname{Real}\left[\left\{\frac{V_{s}(j j)-V_{r}(j j)}{Z(j j)}\right\}^{*}\{Z(j j)\}\{I(j j)\}\right] \\
& \operatorname{PLoss}(j j)=\operatorname{Real}\left[\left[V_{s}(j j)-V_{r}(j j)\right]^{*}\left[\frac{Z(j j)}{Z(j j)^{*}}\right][I(j j)]\right]
\end{aligned}
$$

Substituting the value of branch current I(jj) from (3) in (6),

$$
\operatorname{PLoss}(j j)=\operatorname{Real}\left[\left[V_{s}(j j)-V_{r}(j j)\right]^{*}\left[\frac{Z(j j)}{Z(j j)^{*}}\right]\left[\sum_{i=s b(m f s(j j))}^{s b(m t s(j j))} \frac{P_{L i}-j Q_{L i}}{\left\{V_{i}\right\}^{*}}\right]\right]
$$

Rearranging,

$$
P \operatorname{Loss}(j j)=\operatorname{Real}\left[\sum_{i=s b(m f s(j j))}^{s b(m t s(j j))}\left[\left\{\frac{V_{S}(j j)-V_{r}(j j)}{V_{i}}\right\}^{*}\left\{\frac{Z(j j)}{Z(j j)^{*}}\right\}\right]\left[P_{L i}-j Q_{L i}\right]\right]
$$

Since, all parameters present in the first part of (8) are complex quantities, their solution will be a complex quantity. Thus, 


$$
\left[\left\{\frac{V_{s}(j j)-V_{r}(j j)}{V_{i}}\right\}^{*}\left\{\frac{Z(j j)}{Z(j j)^{*}}\right\}\right]=A(j j, i)+j B(j j, i)
$$

The value of (9) mainly depends on $V_{i}$, as other quantities are constant for branch- $j j$. Hence, this expression is exclusively related to the subsequent node- $i$ of branch- $j j$. Here, $A(j j, i)$ and $B(j j, i)$ represent the real and imaginary part associated with the subsequent node- $i$ of branch-jj, respectively. Therefore, the equation of APL for the branch-jj can be stated as:

$$
P \operatorname{Loss}(j j)=\sum_{i=s b(m f s(j j))}^{s b(m t s(j j))} P \operatorname{Loss}(j j, i)=\sum_{i=s b(m f s(j j))}^{s b(m t s(j j))}\left\{A(j j, i) P_{L i}+B(j j, i) Q_{L i}\right\}
$$

It is realised from (10) that, the consumers beyond branch-jj of the RDN are liable for APL of the branch-jj, and therefore, it should be distributed among these customers. Thus, APLA at each bus ' $i$ ' is evaluated as:

$$
\operatorname{PLoss}(i)=\sum_{j j=1}^{n b-1} \operatorname{PLoss}(j j, i)
$$

Thus, the entire loss of the EPDS is estimated as [28],

$$
\text { TPLoss }=\sum_{i=1}^{n b} P \operatorname{Loss}(i)
$$

\section{POWER DISTRIBUTION NETWORK RECONFIGURATION}

The BE based NR technique mainly aims to provide an optimum network without disturbing radial nature of the system. It is generally performed through two steps. In first step, a closed loop is made by closing an open switch (i.e., tie line ' $t l$ '), and then in the next step, the revival of radiality of the RDN is executed by opening a branch (i.e., sectionalizing switch ' $s s$ ') within the closed loop. The selection of tie-line is performed by calculating voltage across all the tie lines. The 'tl' with maximum potential difference (PD) is identified as the first tie line to be closed. Simultaneously, one branch is to be made open in order to retain radiality of the power network. For this purpose, the voltages of the two node points corresponding to the selected tie line are first measured. Then, the branch linked to the node point with low voltage is made open and total APL of the network is computed. If total APL of the newly obtained RDN is observed to be less than that of the basic RDN then, the next branch is marked to be opened. The same procedure is carried out till the power loss of the newly obtained RDN remains equal to that of the previous one. After getting the sectionalizing switch ' $s s$ ' for the considered tie line ' $t l$ ', the entire process is continued till the final optimal RDN is obtained. Thus, NR is performed from a set of switching data which is presented as $(t l, s s)$ pairs. After each switching process, a new RDN is achieved. Therefore, the proposed arrays are to be modified as per the newly obtained RDN for verification of further switching operation. The detail algorithm of the proposed heuristic 'branch exchange' technique [30] is discussed thoroughly in subsection-3.1 for proper implementation and tested using a 69-bus test distribution system in subsection 4.1.

\subsection{Algorithm of the proposed branch exchange based NR technique}

The detail procedure of the NR method is presented below.

Step 1 : Compute TPLoss of the RDN using equation (12).

Step 2 : The voltage across all tie lines $(t l)$ are computed $\left(i . e . \Delta V_{t l}(i)\right)$, where $i=1,2, \ldots, N t l$, and $N t l=$ total number of tie lines present.

Step 3 : Identify the ' $t l^{\prime}$ whose voltage is the maximum, then assign a code ' $n$ ' to it (i.e. $\Delta V_{t l, \max }=$ $\left.\Delta V_{t l}(n)\right)$. Point out the two ends of the ' $\mathrm{n}$ 'th' tie line as ' $\mathrm{k}$ ' and ' $\mathrm{w}$ ' obeying the relation $\left|\mathrm{V}_{\mathrm{k}}\right|<\left|\mathrm{V}_{\mathrm{w}}\right|$.

Step 4 : The new ' $t l^{\prime}$ is fixed to ' $t l=[k, w]^{\prime}$, and the adjacent branch of $k^{t h}$ node is marked as ' $s s^{\prime}$.

Step 5 : Evaluate total power loss of the newly obtained network (i.e., TPLoss new $_{\text {) }}$ ) using equation (12)

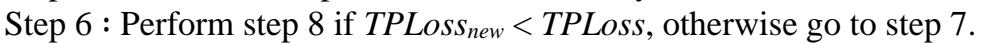

Step 7 : Perform step 11 after removing the switching.

Step $8:$ Set TPLoss $=$ TPLossnew

Step 9 : Perform step 11 when it is checked for entire branches of the loop; else proceed to step 10. Step 10 : Proceed to step 5 after assignment of both ' $t l$ to $[k, w]^{\prime}$, and 'ss' as adjacent branch of ' $s s^{\prime}$. Step $11:$ Set $N t l=N t l-1$, then proceed to step 2 if $N t l>0$ otherwise, perform step 12 . 


\section{RESULTS AND DISCUSSION}

This section comprises of two subsections. The first part explains about the entire solution procedure for obtaining the minimum loss providing reconfigured RDN using a $12.66 \mathrm{kV}, 69$-bus EPDS with 73 branches and 5 tie lines as represented in Figure 1. The corresponding line and load data of the said EPDS are collected from the discussed method [9]. The second part investigates the effectiveness of the present APLA scheme by analyzing loss allocation results of the considered RDN with other established methods (Quadratic method [9], Exact method [22], and CTDM [23]) at two scenarios (i.e., earlier and next to NR). The APLA results of the original and reconfigured network are presented in Table 1 and Table 2, respectively.

Table 1: Loss allocation of 69-bus test system before reconfiguration

\begin{tabular}{|c|c|c|c|c|c|c|c|c|c|}
\hline $\begin{array}{l}\text { Node } \\
\text { No. }\end{array}$ & $\begin{array}{l}\text { Proposed } \\
\text { Method }\end{array}$ & $\begin{array}{l}\text { Exact } \\
\text { Method }\end{array}$ & $\begin{array}{l}\text { Quadratic } \\
\text { Method }\end{array}$ & CTDM & $\begin{array}{l}\text { Node } \\
\text { No. }\end{array}$ & $\begin{array}{l}\text { Proposed } \\
\text { Method }\end{array}$ & $\begin{array}{l}\text { Exact } \\
\text { Method }\end{array}$ & $\begin{array}{l}\text { Quadratic } \\
\text { Method }\end{array}$ & CTDM \\
\hline 6 & 0.0313 & 0.0279 & 0.0003 & 0.0225 & 37 & 0.0038 & 0.0035 & 0.0026 & 0.0034 \\
\hline 7 & 0.8885 & 0.8558 & 0.2681 & 0.6699 & 39 & 0.0076 & 0.0073 & 0.0054 & 0.007 \\
\hline 9 & 0.7733 & 0.7501 & 0.1744 & 0.5804 & 41 & 0.0013 & 0.001 & 0.000023 & 0.0008 \\
\hline 10 & 0.8647 & 0.8724 & 0.223 & 0.6878 & 43 & 0.0072 & 0.0068 & 0.0009 & 0.0049 \\
\hline 11 & 4.8242 & 4.7455 & 4.227 & 4.1416 & 45 & 0.0477 & 0.0485 & 0.052 & 0.0495 \\
\hline 14 & 0.3518 & 0.3523 & 0.026 & 0.2817 & 49 & 1.1273 & 1.1252 & 1.1515 & 1.1332 \\
\hline 16 & 2.1534 & 2.1924 & 1.1631 & 1.8417 & 50 & 1.2447 & 1.2407 & 1.2687 & 1.25 \\
\hline 17 & 2.735 & 2.9203 & 1.854 & 2.4513 & 51 & 0.9639 & 0.9581 & 0.2912 & 0.7372 \\
\hline 18 & 2.7356 & 2.921 & 1.8546 & 2.4519 & 52 & 0.0893 & 0.0857 & 0.0012 & 0.0659 \\
\hline 20 & 0.0472 & 0.0498 & 0.0002 & 0.0383 & 53 & 0.1337 & 0.1237 & 0.0023 & 0.0928 \\
\hline 27 & 0.7397 & 0.7296 & 0.1295 & 0.5917 & 62 & 3.5806 & 3.5728 & 0.3777 & 1.815 \\
\hline 28 & 0.0011 & 0.001 & 0.0003 & 0.0009 & 64 & 25.9941 & 26.0191 & 13.5632 & 16.3692 \\
\hline 29 & 0.0021 & 0.0021 & 0.0016 & 0.0021 & 65 & 6.7922 & 6.8061 & 1.3817 & 3.5751 \\
\hline 33 & 0.0098 & 0.0097 & 0.0087 & 0.0093 & 66 & 0.6025 & 0.5909 & 0.1 & 0.4726 \\
\hline 34 & 0.0217 & 0.0215 & 0.0254 & 0.0237 & 67 & 0.6026 & 0.5909 & 0.1 & 0.4726 \\
\hline 35 & 0.0069 & 0.0071 & 0.0026 & 0.005 & 68 & 1.0558 & 1.0414 & 0.3144 & 0.8499 \\
\hline 36 & 0.0012 & 0.0011 & 0.0004 & 0.001 & 69 & 1.0558 & 1.0415 & 0.3144 & 0.8499 \\
\hline
\end{tabular}

Table 2: Loss allocation of 69-bus test system after reconfiguration

\begin{tabular}{|c|c|c|c|c|c|c|c|c|c|}
\hline $\begin{array}{l}\text { Node } \\
\text { No. }\end{array}$ & $\begin{array}{l}\text { Proposed } \\
\text { Method }\end{array}$ & $\begin{array}{l}\text { Exact } \\
\text { Method }\end{array}$ & $\begin{array}{l}\text { Quadratic } \\
\text { Method }\end{array}$ & CTDM & $\begin{array}{l}\text { Node } \\
\text { No. }\end{array}$ & $\begin{array}{l}\text { Proposed } \\
\text { Method }\end{array}$ & $\begin{array}{l}\text { Exact } \\
\text { Method }\end{array}$ & $\begin{array}{l}\text { Quadratic } \\
\text { Method }\end{array}$ & CTDM \\
\hline 6 & 0.0075 & 0.0068 & 0.0002 & 0.0063 & 37 & 0.6934 & 0.0138 & 0.0056 & 0.5266 \\
\hline 7 & 0.2081 & 0.2041 & 0.1498 & 0.1921 & 39 & 0.6514 & 0.036 & 0.0129 & 0.4911 \\
\hline 8 & 0.4211 & 0.4199 & 0.4513 & 0.4129 & 40 & 0.6516 & 0.0363 & 0.013 & 0.4912 \\
\hline 9 & 0.1777 & 0.1755 & 0.0998 & 0.1614 & 41 & 0.0394 & 0.0073 & 0.0001 & 0.0264 \\
\hline 10 & 0.2501 & 0.2561 & 0.1228 & 0.2216 & 43 & 0.1887 & 0.0524 & 0.0028 & 0.1299 \\
\hline 11 & 1.4401 & 1.4394 & 2.0081 & 1.5662 & 45 & 1.2046 & 0.38 & 0.1979 & 0.9053 \\
\hline 12 & 1.6572 & 1.6567 & 2.2939 & 1.824 & 46 & 1.2496 & 0.3803 & 0.198 & 0.9657 \\
\hline 13 & 0.0906 & 0.0922 & 0.0103 & 0.073 & 48 & 0.1588 & 0.1607 & 0.0215 & 0.071 \\
\hline 14 & 0.0912 & 0.0928 & 0.0116 & 0.0737 & 49 & 3.2086 & 3.1442 & 1.8286 & 1.7343 \\
\hline 16 & 0.4178 & 0.775 & 0.433 & 0.3591 & 50 & 3.3764 & 3.6917 & 2.101 & 2.113 \\
\hline 17 & 0.6723 & 1.1693 & 0.7599 & 0.6024 & 51 & 0.2249 & 0.2278 & 0.1626 & 0.2108 \\
\hline 18 & 0.6741 & 1.1708 & 0.7606 & 0.604 & 52 & 0.0209 & 0.0204 & 0.0008 & 0.018 \\
\hline 20 & 0.0146 & 0.0219 & 0.0001 & 0.0117 & 53 & 0.0277 & 0.026 & 0.0014 & 0.0235 \\
\hline 21 & 2.065 & 2.6319 & 2.9018 & 1.9028 & 54 & 0.1596 & 0.1592 & 0.0823 & 0.1454 \\
\hline 22 & 0.0928 & 0.1235 & 0.0041 & 0.073 & 55 & 0.1463 & 0.1463 & 0.0694 & 0.1329 \\
\hline 24 & 0.5859 & 0.697 & 0.2339 & 0.4647 & 59 & 3.7735 & 3.8377 & 0.4991 & 1.0739 \\
\hline 26 & 0.3679 & 0.3963 & 0.0567 & 0.2756 & 61 & 61.4561 & 63.2574 & 71.2625 & 64.0852 \\
\hline 27 & 0.3821 & 0.4038 & 0.0573 & 0.2876 & 62 & 1.1901 & 1.6275 & 0.0574 & 0.3214 \\
\hline 28 & 0.0011 & 0.0011 & 0.0003 & 0.0008 & 64 & 8.1462 & 7.7787 & 11.0675 & 8.8005 \\
\hline 29 & 0.0021 & 0.0021 & 0.0016 & 0.0019 & 65 & 1.661 & 1.8768 & 1.1726 & 1.6458 \\
\hline 33 & 0.0098 & 0.0097 & 0.0087 & 0.0092 & 66 & 0.1807 & 0.1801 & 0.0568 & 0.1538 \\
\hline 34 & 0.0217 & 0.0216 & 0.0254 & 0.0236 & 67 & 0.1807 & 0.1801 & 0.0568 & 0.1538 \\
\hline 35 & 0.0069 & 0.0071 & 0.0026 & 0.005 & 68 & 0.3305 & 0.331 & 0.1647 & 0.2799 \\
\hline 36 & 0.6856 & 0.0018 & 0.0006 & 0.5217 & 69 & 0.3306 & 0.3311 & 0.1647 & 0.2799 \\
\hline
\end{tabular}




\subsection{Solution Steps for obtaining reconfigured optimum 69-bus RDN}

It can be viewed from Figure 1 that the five tie lines i.e., 50-59, 27-65, 15-46, 13-21 and 11-43 of the considered 69-node RDN are primarily present in the open state condition. At this scenario, the present LA procedure awards a total loss of $225.0016 \mathrm{~kW}$ which is almost near to the result of other established methods (i.e., $225.0015 \mathrm{~kW}$ by exact method, $224.9517 \mathrm{~kW}$ by Quadratic method, and $224.1507 \mathrm{~kW}$ by CTDM method). The PD across all the 5-tie lines are calculated, and maximum amount is observed across 50-59 since the difference in voltage is found to be $\left|\mathrm{V}_{50}-\mathrm{V}_{59}\right|=0.0694$ p.u. Therefore, a loop is made with the help of ' $t l=[50,59]^{\prime}$. But, in order to make the network radial, one branch of this loop is to be opened. As voltage of node-59 $\left(\mathrm{V}_{59}=0.9248 \mathrm{pu}\right)$ is less than that of bus-50 $\left(\mathrm{V}_{50}=0.9942 \mathrm{pu}\right)$ i.e., $\mathrm{V}_{59}(0.9248$ p.u. $)<\mathrm{V}_{50}$ (0.9942 p.u.), the 'ss $=[58,59]^{\prime}$ is identified to be made open before functioning of the 'tie line $50-59^{\prime}$.

But, at this condition, the total APLA of the restructured network is observed to be $132.1583 \mathrm{~kW}$. Science there is a reduction in total APLA, so investigation is carried out for branch 57-58. However, power loss for the RDN with opening of the branch $57-58$ is evaluated to be $132.1583 \mathrm{~kW}$ (no deviation). Thus, the $' t l=50-59$ ' is finally identified for the 'ss $=58-59$ '. The similar procedure is followed further for rest of the tie lines to get the optimum RDN. The PD across the remaining four tie lines are computed and maximum difference is observed at ' $t l=27-65^{\prime}$ i.e., $\left|\mathrm{V}_{27}-\mathrm{V}_{65}\right|=0.0362$. Since $\mathrm{V}_{65}(0.9349$ p.u. $)<\mathrm{V}_{27}$ (0.9711 p.u.), the branch $64-65$ is first made open by closing the tie line $27-65$. It is noticed, the total APLA of the system again decreases to $128.7273 \mathrm{~kW}$ with this restructured network. It is noteworthy to observe that total loss further decreases to $127.52 \mathrm{~kW}$ as the branch ' $63-64$ ' is made open by closing' $64-$ $65^{\prime}$. However, it retains previous value of $127.52 \mathrm{~kW}$ as is estimated for ' $62-63^{\prime}$. Therefore, the branch ' $27-65^{\prime}$ is identified as the tie line while the branch ' $63-64^{\prime}$ is designated as the sectionalizing switch.

Since, potential difference of branch ' $15-46^{\prime}$ (i.e., $\left|\mathrm{V}_{15^{-}} \mathrm{V}_{46}\right|=0.0383$ p.u.) is found maximum against the rest 3-lines, the branch connecting node points 15 and 46 is selected to be closed. As potential of node-15 $\left(\mathrm{V}_{15}=0.9601 \mathrm{pu}\right)$ is noticed to be less than that of node-46 $\left(\mathrm{V}_{46}=0.9984 \mathrm{p} . \mathrm{u}\right.$. $)$, the branch $14-15$ is considered to be opened. This leads to a drop in total APLA to $99.66 \mathrm{~kW}$. From above observation, the loop branch ' $14-15^{\prime}$ is identified to be opened with respect to the tie line ' $15-46$ ' because, the opening of the branch '13 - 14' enhances RDN loss to $99.7390 \mathrm{~kW}$.

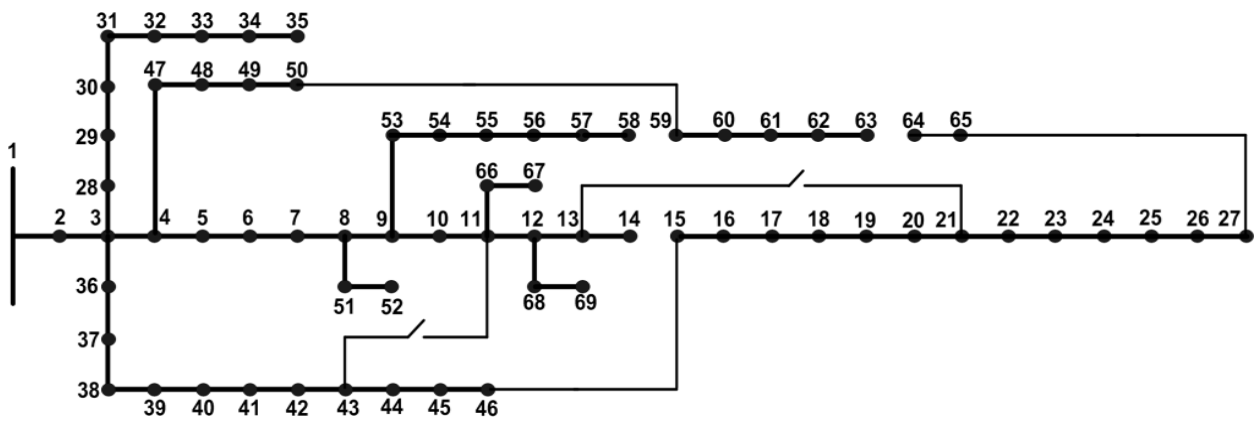

Figure 2: A sample 69-bus test distribution system after NR

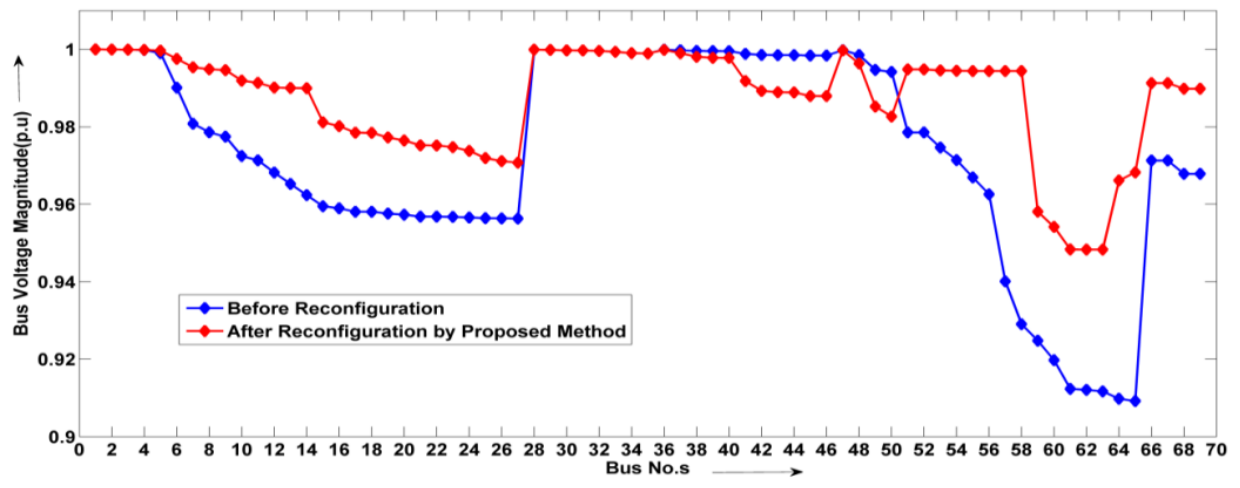

Figure 3: Voltage profile of the 69-bus RDN before and after reconfiguration 
Likewise, the responses of other 2-tie lines are also verified in the similar manner and in each case, the total APLA is observed to be higher than that of $99.66 \mathrm{~kW}$ and thus, excluded from further consideration. For checking of these 2-tie lines two load flows are to be carried out. Hence, total '10' power flow calculations are to be performed to get the optimal restructured RDN as shoen in Figure 2. The total APLA of the modified 69-bus Figure 2 is found to be $99.5946 \mathrm{~kW}$ by the present APLA scheme which is very close to the results of other existing methods.

\subsection{Analysis on loss allocation results}

The total APLAs of the original and reconfigured 69-bus RDN are found to be very close to $225 \mathrm{~kW}$ and $99.59 \mathrm{~kW}$ respectively by all the discussed methods. Hence, proposed approach of LA is contemporary and comparable to other existing methods. As system loss has decreased from $225 \mathrm{~kW}$ to $99.59 \mathrm{~kW}$, a total profit of $125.41 \mathrm{~kW}$ has been provided to the utility by the present scheme due to NR. It can be observed from Figure 3, before NR, minimum voltage is assigned at node-65 (i.e. $\mathrm{V}_{\min }=\mathrm{V}_{65}=0.9092$ p.u.) whereas three nodes $\left(\mathrm{V}_{\min }=\mathrm{V}_{61}=\mathrm{V}_{62}=\mathrm{V}_{63}=0.9483\right.$ p.u. $)$ are allocated with minimum voltages of 0.9483 pu after NR. Also, it can be identified the improvement in voltage profile is better after reconfiguration than that of before NR. CTDM and Quadratic method allocate large amount of loss to the customer at bus 61 while an adequate amount of loss is assigned by the proposed procedure

Exact method awards equal amount of loss to the highly demanded customer at bus 61 as that of the proposed method. To test competence of the developed technique as regard to their physical locations, two types of customers with equal demands but situated at different position in the network are identified. It can be viewed from Figure 4(a) that before NR, the discrepancy of APLA between two close nodes 36 and 37 of equal demands is the highest by the proposed method as compared to other discussed methods.

After NR, Exact method shows better result against other techniques but a moderate APLA is noticed by the present procedure. Further, it can be realised from Figure 4(b) which represents the difference in APLA between two distance nodes 10 (close to the substation bus) and 28 (far away from the substation bus) that the performance of the proposed and exact procedure are very close to each other at all conditions of the network. These two procedures show better result as compared to other two methods. Out of other two techniques, CTDM provides better LA against Quadratic scheme. However, LA by proposed approach is found to be prominent in contrast to other discussed methods at both before and after reconfiguration of the network. Hence, it can be suggested in practical field of application for efficient and reliable management of smart power systems.

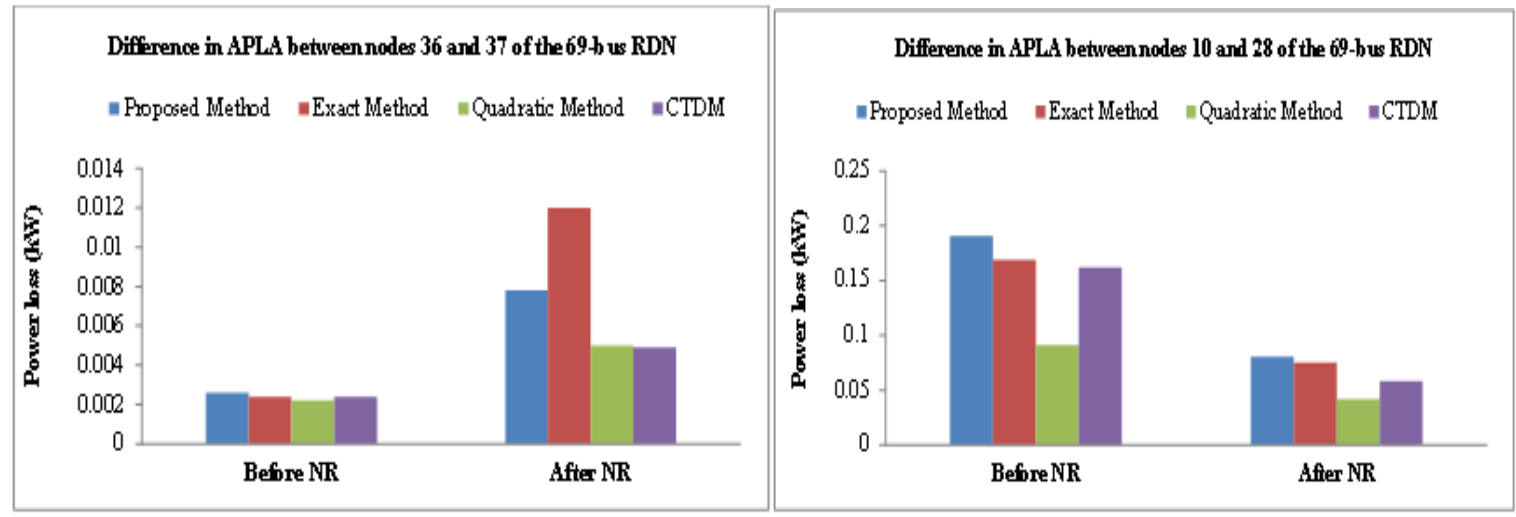

(a)

(b)

Figure 4. (a) Difference in APLA between nodes 36 and 37; (b) Difference in APLA between nodes 10 and 28

\section{CONCLUSIONS}

This paper presents a comparative analysis on RDN loss allocation with respect to network reconfiguration. The branch exchange based heuristic approach of NR provides efficient results as compared to other techniques discussed. The developed APLA scheme is found to be free from the influence of crossterm of power loss equation. Hence, loss allocations are promising as regard to their load demands and geographical locations. The proposed loss allocation (LA) method is developed without any assumptions and approximations which can be treated as major advantage of the present procedure for fair loss allocation. The 
efficiency of the present procedure has been verified against other existing techniques using a 69-bus RDN. The results of APLA are found to be proper as per load demands and physical locations of the end-users. Further, to test efficiency of the developed procedure in a restructured power environment, a BE based NR technique is implimented here for achieving a minimum power loss providing RDN. As a judicious distribution of active power loss is noticed at all the load points hence, can be considered for practical implementation.

\section{ACKNOWLEDGEMENTS}

2021)".

This research work was supported by “Woosong University’s Academic Research Funding - (2020-

\section{REFERENCES}

[1] M. Khosravi, H. Monsef, M.H Aliabadi, "Loss allocation in distribution network including distributed energy resources (DERs)," International Transactions on Electrical Energy Systems, vol. 28, 2018, doi: 10.1002/etep.2548.

[2] P. Kumar, N. Gupta, K.R. Niazi, and A. Swarnkar, "A Cross-term Decomposition Method for Loss Allocation in Distribution Systems Considering Load Power Factor," Electric Power Components and Systems, vol. 46, pp. 218229, 2018, doi: 10.1080/15325008.2018.1434840.

[3] S.R. Salkuti, Y.H. Lho, "Optimum Location of Voltage Regulators in the Radial Distribution Systems", International Journal of Emerging Electric Power Systems, vol. 17, no. 3, pp. 351-361, 2016, doi: 10.1515/ijeeps2015-0197.

[4] Y. Merzoug, B. Abdelkrim, B. Larbi, "Distribution network reconfiguration for loss reductionusing PSO method," International Journal of Electrical and Computer Engineering (IJECE), vol. 10, no. 5, pp. 5009-5015, 2020.

[5] T.T. Nguyen, "Electric distribution network reconfiguration for power loss reduction based on runner root algorithm," International Journal of Electrical and Computer Engineering (IJECE), vol. 10, no. 5, pp. 5016-5024, 2020, doi: 10.11591/ijece.v10i5.pp5016-5024.

[6] S. Mishra, D. Das, S. Paul, "A comprehensive review on power distribution network reconfiguration," Energy Systems, vol. 6, no. 2, pp. 1-5, 2017, doi: 10.1007/s12667-016-0195-7.

[7] A.P. Hota, S. Mishra, D.P. Mishra, "Loss Allocation Strategies in Active Power Distribution Networks: A Review," In: AECSS. Lecture Notes in Electrical Engineering, vol. 665, pp. 889-902, 2020, doi: 10.1007/978-981-15-52625_68.

[8] M. E. de Oliveira, L. F. Ochoa, A. Padilha-Feltrin and J. R. S. Mantovani, "Network reconfiguration and loss allocation for distribution systems with distributed generation," 2004 IEEE/PES Transmision and Distribution Conference and Exposition: Latin America (IEEE Cat. No. 04EX956), Sao Paulo, Brazil, 2004, pp. 206-211, doi: 10.1109/TDC.2004.1432379.

[9] J. S. Savier and D. Das, "Impact of Network Reconfiguration on Loss Allocation of Radial Distribution Systems," in IEEE Transactions on Power Delivery, vol. 22, no. 4, pp. 2473-2480, Oct. 2007, doi: 10.1109/TPWRD.2007.905370.

[10] J.S. Savier, D. Das, "Loss Allocation to Consumers before and after reconfiguration of Radial Distribution Networks," in Electrical Power and Energy Systems, vol. 33, pp. 540-549, 2011, doi: 10.1016/j.ijepes.2010.11.007.

[11] M. Heidari-Kapourchali and V. Aravinthan, "Loss allocation control in power distribution system reconfiguration in the presence of distributed generators," 2014 IEEE PES General Meeting | Conference \& Exposition, National Harbor, MD, USA, 2014, pp. 1-5, doi: 10.1109/PESGM.2014.6939508.

[12] E. Carpaneto, G. Chicco and J. S. Akilimali, "Branch current decomposition method for loss allocation in radial distribution systems with distributed generation," in IEEE Transactions on Power Systems, vol. 21, no. 3, pp. 11701179, Aug. 2006, doi: 10.1109/TPWRS.2006.876684.

[13] A. A. Mohd Zin, A. K. Ferdavani, A. B. Khairuddin and M. M. Naeini, "Reconfiguration of Radial Electrical Distribution Network Through Minimum-Current Circular-Updating-Mechanism Method," in IEEE Transactions on Power Systems, vol. 27, no. 2, pp. 968-974, May 2012, doi: 10.1109/TPWRS.2011.2174258.

[14] K.M. Jagtap, D.K. Khatod, "Novel approach for loss allocation of distribution networks with DGs," Electric Power Systems Research, vol. 143, pp. 303-311, 2017, doi: 10.1016/j.epsr.2016.10.032.

[15] S. Sharma and A. R. Abhyankar, "Loss Allocation for Weakly Meshed Distribution System Using Analytical Formulation of Shapley Value," in IEEE Transactions on Power Systems, vol. 32, no. 2, pp. 1369-1377, March 2017, doi: 10.1109/TPWRS.2016.2571980.

[16] Q. Yu, J. Xie, X. Chen, K. Yu, L. Gan, L. Chen, "Loss allocation for radial distribution network including DGs using Shapley value sampling estimate," IEE Proc. of Generation, Transmission, and Distribution, vol. 13, no. 8, pp. 1382-1390, 2019, doi: 10.1049/iet-gtd.2018.6486.

[17] H. Amaris, Y. P. Molina, M. Alonso and J. E. Luyo, "Loss Allocation in Distribution Networks Based on AumannShapley," in IEEE Transactions on Power Systems, vol. 33, no. 6, pp. 6655-6666, Nov. 2018, doi: 10.1109/TPWRS.2018.2844740.

[18] Y. P. Molina, R. B. Prada and O. R. Saavedra, "Complex Losses Allocation to Generators and Loads Based on Circuit Theory and Aumann-Shapley Method," in IEEE Transactions on Power Systems, vol. 25, no. 4, pp. 19281936, Nov. 2010, doi: 10.1109/TPWRS.2010.2044425. 
[19] S. Sharma, A.R. Abhyankar, "Loss allocation of radial distribution system using Shapley value: A sequential approach," International Journal of Electrical Power Energy Systems, vol. 88, pp. 33-41, 2017, doi: 10.1016/j.ijepes.2016.11.015.

[20] S.S. Kashyap, M. De, "Loss allocation and loss minimization for radial distribution system including DGs," IET Renewable Power Generation, vol. 11, pp. 806-818, 2017, doi: 10.1049/iet-rpg.2016.0506.

[21] M. Atanasovski and R. Taleski, "Power Summation Method for Loss Allocation in Radial Distribution Networks With DG," in IEEE Transactions on Power Systems, vol. 26, no. 4, pp. 2491-2499, Nov. 2011, doi: 10.1109/TPWRS.2011.2153216.

[22] J.S. Savier, D. Das, “An Exact Method for Loss Allocation in Radial Distribution Systems," Electrical Power and Energy Systems, vol. 36, pp.100-106, 2012, doi: 10.1016/j.ijepes.2011.10.030.

[23] P. Kumar, N. Gupta, K. R. Niazi and A. Swarnkar, "A Circuit Theory-Based Loss Allocation Method for Active Distribution Systems," in IEEE Transactions on Smart Grid, vol. 10, no. 1, pp. 1005-1012, Jan. 2019, doi: 10.1109/TSG.2017.2757059.

[24] A.P. Hota, S. Mishra, D.P. Mishra, "A New Active Power Loss Allocation Method for Radial Distribution Networks with DGs,” In: AECSS. Lecture Notes in Electrical Engineering, vol 665., pp. 501-514, 2020, doi: 10.1007/978-981-15-5262-5_37.

[25] A.P. Hota, S. Mishra, "A branch oriented active power loss allocation method for radial distribution networks with distributed generators," Scientia Iranica, 2020.

[26] S.R. Salkuti, "Optimal location and sizing of DG and D-STATCOM in distribution networks", Indonesian Journal of Electrical Engineering and Computer Science, vol. 16, no. 3, pp. 1107-1114, 2019, doi: 10.11591/ijeecs.v16.i3.pp1107-1114.

[27] S. Ghosh, D. Das, "Method for load-flow solution of radial distribution networks," IEE Proceedings-Generation, Transmission and Distribution, vol. 146, pp. 641-648, 1999, doi: 10.1049/ip-gtd:19990464.

[28] A.P. Hota, S. Mishra, D.P. Mishra, "A New Active Power Loss Allocation Method for Radial Distribution Networks with DGs,” In: Pradhan G., Morris S., Nayak N. (eds) Advances in Electrical Control and Signal Systems. Lecture Notes in Electrical Engineering, vol. 665, pp. 501-514, 2020, doi: 10.1007/978-981-15-52625_37.

[29] A. P. Hota, S. Mishra, "A Forward-Backward Sweep based numerical approach for active power loss allocation of radial distribution network with distributed generations," International Journal of Numerical Modelling: Electronic Networks, Devices and Fields, Wiley, 2020, doi: 10.1002/jnm.2788.

[30] A.P. Hota, S. Mishra, "Loss allocation in distribution networks with distributed generators undergoing network reconfiguration," International Journal of Electrical and Computer Engineering (IJECE), vol. 10, no. 4, pp. 3375-3383, 2020, doi: 10.11591/ijece.v10i4.pp3375-3383. 